\title{
La littérature au service du paranormal
}

\author{
Maxime Prévost \\ Université d'Ottawa
}

Plusieurs auteurs du XIXe siècle, notamment Balzac, Hugo, Dumas, Maupassant, Conan Doyle, se sont portés à la défense de savoirs qui nous semblent aujourd'hui hors normes et pour tout dire illégitimes (magnétisme, spiritisme, hypnotisme). Les études ici réunies considèrent collectivement le XIX ${ }^{\mathrm{e}}$ siècle littéraire comme le théâtre d'une formidable extension du domaine de la mimésis, particulièrement en ce qui a trait à la théorie scientifique: la littérature n'est-elle pas devenue le laboratoire d'une vaste (et peut-être frauduleuse) substitution de l'« empirisme littéraire » à la théorie scientifique, au nom du mimétisme réaliste? Les auteurs de ce collectif tentent de voir comment la littérature a eu la prétention de créer $d u$ vrai, c'est- 
à-dire de compléter l'empirisme, voire de s'y substituer. Ils étudient ces écrivains qui se sont arrogé le droit de trancher les controverses épistémologiques, ou du moins celui de relancer des hypothèses rejetées par les institutions scientifiques légitimes. Que se passe-t-il lorsque la littérature, forte du pacte mimétique qui unit l'auteur à son lectorat, entreprend d'imiter des phénomènes à la positivité pour le moins douteuse? Le monde des livres est-il doté d'un plus grand coefficient de réalité que le livre du monde?

Ce dossier est le fruit d'une réflexion lancée dans le cadre d'un séminaire d'études supérieures de l'Université d'Ottawa, séminaire au cours duquel il s'agissait d'interroger les rapports qu'ont entretenus différents écrivains au paranormal et aux virtualités mimétiques de la littérature, au cours du « long XIX ${ }^{\text {e }}$ siècle » (à savoir de 1785, avec Mesmer, à la Grande Guerre et à ses séquelles, période d'intense activité spirite). Collectivement, nous nous sommes intéressés au Louis Lambert de Balzac, aux Contemplations de Victor Hugo, au Horla de Maupassant et à L'Ève future de Villiers de L'Isle-Adam, en réfléchissant à la conception que ces écrivains purent avoir de leur rôle. Engagent-ils leur crédibilité dans quelque débat scientifique ou épistémologique et, si oui, lequel? Se servent-ils de l'étrange et de l'inexpliqué par jeu, pour produire du beau ou du divertissement, ou se mettent-ils plutôt au service de savoirs déviants? Utilisent-ils la littérature pour professer et pour établir la réalité de phénomènes à la positivité douteuse? Les études qui suivent soumettent Edgar Allan Poe, Théophile Gautier, Gustave Flaubert et August Strindberg à ce questionnement. 